\title{
Micro-policies of adult-child joint play in the context of the Finnish ECEC system
}

\section{Paananen, Maiju}

Routledge

2019-09

Paananen, M \& Rainio , A P 2019 , Micro-policies of adult-child joint play in the context of the Finnish ECEC system . in S Alcock \& N Stobbs (eds), Rethinking Play as Pedagogy . 1. ed. edn , Thinking about Pedagogy in Early Education, Routledge , London . https://doi.org/10.4324/978042945404?

http://hdl.handle.net/10138/312571

https://doi.org/10.4324/9780429454042-15

unspecified

acceptedVersion

Downloaded from Helda, University of Helsinki institutional repository.

This is an electronic reprint of the original article.

This reprint may differ from the original in pagination and typographic detail.

Please cite the original version. 


\section{Maiju Paananen \& Anna Pauliina Rainio \\ Micro-policies of adult-child joint play in the context of the Finnish ECEC system}

Research supports the role of reciprocal imaginative play in developing a sense of 'togetherness' and empathy (i.e., Hännikäinen, 2007) and promoting social justice in preschool classrooms (Ferholt \& Lecusay, 2010). In the Finnish National Curriculum guidelines on Early Childhood Education and Care (ECEC) 2016, adult participation in children's play is recognized as valuable from the perspective of equity and in its own right. Teachers are encouraged to create joint playworlds together with children. Simultaneously, in line with a worldwide trend, preschools in Finland have met rising expectations of efficiency, leading to pressures to demonstrate performance. Under such conditions, it is more difficult to ensure that play activities in preschools occur with adult involvement in children's play. National policies provide a context for making decisions concerning ECEC arrangements. These policy spaces have not been widely examined from the perspective of the daily life of people influenced by them. In this chapter, we highlight how possibilities for play are formed in complex interactions between national and local policies. Through two case studies, we explore the potential and challenges of different kinds of play-based pedagogical activities to persist under pressures from intensification measures and scarcening resources.

In the newest Core Curriculum (2016) that regulates Finnish ECEC, adult-child joint play and adult participation in children's play is recognized as valuable from both a developmental and an equity perspective. The significance of play for children also lies in the play itself: children 'structure and explore the surrounding world, create social relations and form meanings based on their experiences,... construct ideas of themselves and others through play and experiment with different roles and ideas which they could otherwise not carry out' (ECEC Core Curriculum, 2016 pp. 63). The curriculum suggests that pedagogical activities (drama, story telling) can be combined in developing play and constructing imaginary worlds. Play is constructed as neither only instrumental nor only important in its own right but as a combination of both. Thus, the curriculum illuminates how Finnish ECEC, in addition to being built on Pestalozzi's and Froebel's tradition (see Onnismaa \& Kalliala, 2010), reflects the influence of Vygotsky's $(1978 ; 1987)$ theories of play.

The Core Curriculum also gives guidelines for adults' role in play. It is stated that 'the personnel must acknowledge the significance of concentrated exploration, spontaneous creative expression as well as boisterous play and physical games on children's well-being and learning'. The personnel must ensure that each child gets an opportunity to participate in playing with others according to their skills and capabilities and support the development of children's play by either guiding it from the outside or participating in it (2016 pp. 64). Teachers construct play opportunities ensuring equity, in particular the societal function of ensuring social justice: that every child feels included in the group, is being heard, and gains experiences of belonging and joy (Paananen, 2017a).

In line with global trends, however, preschools have to respond to increased pressures to demonstrate performance (Paananen, 2017a). Research indicates that under such conditions, it is more difficult to ensure long-term play activities in preschools with adults in children's play (Paananen, 2017a). These national policies provide a context - a policy terrain - for making decisions concerning ECEC arrangements. Previous literature has explored how policies become 
translated and adapted when they are moved from one context to another (McCann, 2011; McCann $\&$ Ward, 2012), sometimes in surprising forms at the national level (Hay, 2004).

As we will demonstrate, national policies that strongly support and emphasize play do not necessarily lead to practices where play has an important role. Rather, they become entangled with local policies and lead to varying practices. We examine how play is simultaneously constrained and made possible by micro-policies. By micro-policies, we mean how decisions concerning the daily practices of preschools are made: how different policy aims become mediated into actual practices; how national and local policies are interpreted; what is considered important when making daily decisions; whose perspective counts, and why?

We use evidence from two ethnographic case studies of Finnish public preschools to establish our argument. We will show - drawing on the first author Maiju's study (Paananen 2017a\&b) - how competing aims in national- and municipal-level policies may overrule aims related to play. Then, using the second author Anna's data (Rainio, 2010), we will examine the potential conditions in which play remains strong in the daily life of these settings. Contrasting these two examples allows us to ponder what can be done to support adult-child joint play in early childhood settings.

What does your national curriculum state regarding children's play in early learning and adults' role in children's play?

\section{Example 1: Micro-policies that make play yield to other aims in the daily practices of preschools}

In the first study, Maiju used multiple data-generation methods to examine micro-policies in the site: the role of different kinds of governing tools, such as curriculum documents, calendar markings, and schedules - as well as interpretations related to them - to make decisions concerning daily life and practices of the early childhood settings. She asked 13 teachers to keep a diary for one work day and to allow the researchers access to their planning for individual children. Maiju used document-aided interviews of participant teachers to obtain more information concerning the situations they described in their diaries. Interviews were recorded and transcribed verbatim.

Observation data were generated over a four-month period at a small public preschool. Maiju observed daily life in a group of 26 3-5-year-old children and 4 adults. Two of the group's staff members worked as preschool teachers. The other two were nursery nurses. Three of the children needed special support. Consent to conduct the study was gained from the children's parents, staff members, and municipality. Maiju also attended weekly meetings of the group when possible, collecting the meeting minutes, plans created, and staff instructions.

All the situations related to play were selected for analysis. While examining this dataset, it became evident that play and aims that tied closely with children's play seemed to be in turmoil (see also Paananen 2017a).

Participant teachers described play situations in their diaries. Based on this data, one can definitely say that play has a central role in the daily life of preschools in Finland; but strikingly, the observed situations consisted, almost solely, of situations in which children engaged in role play, played with toys or other construction sets in groups of $2-5$ children with no adult participation. If adults 
participated, they were mainly visiting the play situations briefly to solve a problem, suggest a new element in the play, or as temporary participants, such as customers in a shop.

In interviews, the importance of play was emphasized, especially when speaking about children with special needs and children whose social skills did not meet preschool expectations. Teachers felt that some children needed adult help joining and engaging in joint play to develop a sense of belonging and agency, thus teachers viewed play as essential to ensuring equity.

When examining the situation from the perspective of individual children, however, the situation seems a bit different. In Maiju's field notes, some children almost never engaged in play activities with other children. One of these children was a four-year-old child we will call Oliver. He had difficulties communicating with others. It was also agreed in his individual ECEC plan ${ }^{1}$ that adults help him in transition situations and engaging in play with other children.

The following is based on Maiju's ethnographic field notes and describes one morning with Oliver:

Oliver is eating breakfast with a teacher and 12 other children. He is trying to start a conversation with the teacher: 'Listen, do you know Pippi Longstocking'? The teacher does not answer. She gives advice to other children. Oliver tries again, but the teacher does not respond. Oliver makes eye contact with another boy, and they begin making faces. They giggle and start to waggle more and more wildly. A breakfast roll Oliver is eating falls from the table.

Now the teacher notices Oliver and reacts: 'Your breakfast is finished. It is time to go to the toilet, and then get dressed for the outdoor play'.. However, while some other children follow the instruction, the teacher directs Oliver to a reading corner instead as it is agreed in Oliver's individual early childhood education plan that Oliver needs adult help in transitions. Oliver can go to dress-up when a nurse from another group, Hanna, comes to help him. Oliver is reading when Hanna comes. He does not want to leave just yet; he has not finished reading the book he has selected. Hanna does not have much time since she needs to go back to her own group. Oliver can't finish his reading.

Later, outdoors, another boy, Simo, is pushing a wheelbarrow. Oliver tries to sit on the wheelbarrow. 'Simo can't give you a ride with a wheelbarrow. You are too heavy', says a nurse. Oliver leaves the situation.

Oliver wanders around the yard alone and follows others' play. He starts to collect stones and sand with his bare hands. Suddenly, he overbalances and, as a result, turns around and accidentally makes a pirouette. At first, he seems confused, but then he starts to spin with an expression of joy on his face. He stretches his arms wide as he spins around and extends the stretch to his fingers and opens his hands. The sand and stones from his hands shoot

\footnotetext{
${ }^{1}$ Every child ought to have an individual ECEC plan that aims to consider the child's individual needs and opinions and the parent's views in arranging the child's education and care. The plan includes an agreement on important aims for the child, and how the individual's needs are taken into account in the preschool's activities.
} 
quite far. 'Oliver, you cannot throw sand'! yells the nurse. Oliver seems frightened and bends over. 'Shhh...' he whispers.

During this morning, Oliver's play initiations and clues that would have allowed adults to develop joint play with Oliver went unnoticed. The teacher ignored Oliver's conversation initiative about the fictional character Pippi Longstocking, who is very well known in Finland. The second play initiative, giggling and waggling with the other boy, which was likely interpreted as misbehavior that needed to be interrupted rather than encouraged, was interrupted by the teacher. Hanna, a nurse from the other child group did not seize the opportunity to ask what Oliver was reading to engage in an imaginary world with him. When Oliver arrived at the playground, other children were already engaged in different kinds of activities. No one helped Oliver join in play activities. He tried to play with Simo but was interrupted by the nurse. Finally, when Oliver found his own spontaneous 'dizzy

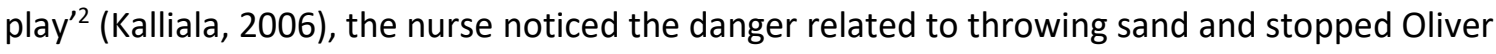
rather than encouraging him to continue without sand and stones in his hands.

When examining Oliver's morning, it seems desolating. We cannot help thinking that the staff could have better supported Oliver's play initiatives and joining in play with his peers. When we examine the situation from the micro-policy viewpoint, however, the situation is more complex.

Based on field notes, diaries, and teacher interviews, we see that staff members tried to create structures that would best serve the needs of the children. Their interactions were typically very sensitive. On the morning described above, they seemed to have their hands full. One staff member was on sick leave, and others arranged to cover the absence; Oliver's first initiative went unnoticed because teachers were discussing these re-arrangements. The municipality's policy was that when a sudden absence of a staff member occurs, they will take care of the situation with internal arrangements instead of calling in a substitute, meaning staff members of the other groups offer help when needed, and they reorganize their work shifts accordingly. This is why Hanna came to help Oliver instead of an adult from Oliver's own group. Thus, helping Oliver was a disruption to Hanna's day: she probably had other duties waiting to be addressed in her own group and wanted to help Oliver go outdoors as quickly as possible. The policy of individual ECEC plans, which, in Oliver's case, involved an agreement to support Oliver individually during transitions, became entangled with the policy related to staff sick leave. Together, they formed a micro-policy that inhibited Oliver from entering outdoor play at the same time as his peers.

Outdoors, when Oliver arrived, a nursery nurse supervised the yard alone. She engaged in conversations with other children, ensured safety, and provided materials and equipment needed by the children. It is possible that she was distracted by another responsibility when Oliver arrived and, therefore, could not immediately help Oliver join in a play activity. The nurse was in the yard alone since the teacher of the group had consultative meetings with a special education teacher and one child's parents. There is a policy that teachers develop and annually update an individual ECEC plan in cooperation with the child's parents. If needed, other professionals, such as a special education teacher, physiotherapist, or psychologist, take part in crafting the individual plan. Usually, in this

\footnotetext{
2 'Dizzy play' describes the creation of disorder and reorder within playful experiences. Elements of dizzy play are full body exploration and humour. It can involve tussling, spinning, or rolling over each other on the grass (Kalliala, 2006).
} 
preschool, meetings related to individual plans were held during the afternoons when children had their nap and quiet time, but were sometimes held at other times if that suited the other professionals or the parents better.

The personnel expressed feelings of exhaustion and were unhappy with the quality of ECEC they were able to provide. In the interviews, they reported that engaging in play activities with the children was something they felt was lacking. In situations involving competing aims, aims related to play seemed to yield to other aims (Paananen, 2017a). Activities that were more directly organized by teachers (e.g., planting a vegetable garden) were usually selected when the teacher needed to decide between engaging in different activities. The teachers stated that play still 'happens' even if it receives minimum input from the adults. These findings are in clear conflict with the curriculum's strong emphasis on adult-child joint play.

Furthermore, in this municipality, there was a new policy related to the number of children allowed per square meter. The policy had increased the number of both children and adults in child groups. This policy has led to the requirement to stagger the use of spaces. When there are too many children and adults to share the same premises at the same time, such as the dining area, they take turns. Hence, the adults need to have an agreement on the responsibilities of each adult at any given time to ensure smooth transitions. If a teacher is having lunch with one group of children and ensuring they will finish before another group's scheduled lunch time, another staff member needs to ensure the other children are engaged in meaningful activities while waiting. This means, however, that there is little leeway for making decisions based on a teachers' contextual evaluation. For example, it is not always possible to continue fruitful play, even if it would support meeting the aims set for the ECEC, without interfering in the smooth operation of daily activities; the pre-fixed schedule needs to be followed (Paananen, 2017a), as in thisexample:

There is this tension that we have to (.) We have 1 to 1.5 hours to be indoors [for play and other activities in the mornings]. Even though they have wonderful and fruitful play going on, we can't stay inside and continue it because the next group is coming in, and we need to go out. Although we stagger [the use of different spaces], have a very good learning environment, and are a child-paced kindergarten, there are preconditions that cannot be ignored. Sometimes, it feels that it is kind of covered or hidden by saying that in our preschool, you don't have to do this and that, but when we really look closely, we can see that for sure you have to (Teacher $\mathrm{K}$ ).

These findings lead us to ask: under what conditions would adult-child joint play sustain its prominent role in preschools' daily activities, and under what conditions would it be able to resist pressures from recent demands on preschools?

\section{Example 2: Micro-policies that help sustain play in the daily activities of a preschool}

In this section, we examine micro-policies in a preschool class that actively used adult-child joint play in its daily activities. The examples are drawn from an ethnographic study by Rainio (2010) that was conducted in a multi-age preschool class in a Finnish elementary school in a small town in 20032004. Consent to conduct the ethnographic study was gained from the children's parents, staff members, and the municipality. All names used are pseudonyms. 
The group was a result of a longitudinal pilot study (1996-2003) that aimed to study, develop, and promote children's transition from preschool to school through a model of narrative learning and play pedagogy (see Hakkarainen, 2004). The class in which the study was conducted combined the normally distinct educational levels of Finnish ECEC (children aged 4-5, the pre-primary education class for 6-year-olds, and the first two grades of elementary school), thus including children from the ages of four to eight years and a multi-professional teacher team. The class that the second author of this chapter, Anna, studied was established in 1999.

In the fall of 2003, when Anna encountered the site, there were thirty children, of which, 15 were 56-year-old preschoolers, and the remaining 15 were first and second graders (7-8-year-old children). An elementary school teacher worked with the first and second grades, and a kindergarten teacher and a nursery nurse worked with the preschoolers. There was also a part-time nursery nurse who helped with children's afternoon activities and mealtimes. Teachers had participated in a three-year in-service education, and the pedagogical activities and daily curriculum of the classroom had thus been developed in collaboration with the researchers.

The preschool class followed its own local curriculum based on the national ECEC curriculum but was also influenced by theoretical underpinnings of the play world pedagogy (see Hakkarainen, 2004). The week was organized around different activities that had their own place in the weekly order. The 7-8-year-olds spent 1-2 hours per day in regular classroom activities (e.g., reading and maths); the remainder of the time was spent in common narrative- and play-based activities for the whole group (e.g., playworlds ${ }^{3}$ ).

In her ethnographic study, Anna paid attention to the particularly persistent nature of play-based activities in the group despite the challenges they constantly faced (see Rainio, 2008a\&b; Rainio \& Hilppö, 2017;). Adult-child joint play generally had a central role in the class. The playworld activity took place every week at the same time, and it rarely, if ever, had to be cancelled or changed. In socially-demanding situations, such as quarrelling between children or chaotic situations, the playworld activity was generally sustained (for examples of such situations, see Rainio, 2008a; 2008b; Paananen \& Rainio, 2018; Hakkarainen, 2009). These ethnographic findings created an interesting contrast with Maiju's study, in which play yielded to other conflicting aims in the group. This led us to ask what kind of micro-policies were in action that helped to support the execution of the play-based curriculum at Anna's site, and what can we learn from it?

We explore this issue by using data from Anna's site. Our data is from an Annual Report (2002-2003) that teachers wrote based on the experiences from the final year of their pilot project. We have conducted a thematic analysis of the annual report to shed light on the micro-policies of play in this setting. We first made note of (a) all instances where the teachers described children's play, adult-

\footnotetext{
${ }^{3}$ Playworlds is an educational practice based on a creative pedagogy of play developed by the Swedish scholar Gunilla Lindqvist (1995). Playworlds can be described as a form of adult-child joint play in which adults and children enter into a common fantasy that is designed to support the development of both adults and children (i.e. Ferholt, Nilsson \& Lecusay, 2019). Adult-child joint play is typically structured around a piece of literature or a work of art.
} 
child joint play, or activities that contain elements or relate to play activities in the group. Then, (b) we separated instances where teachers mentioned a challenge or a difficulty in their preschool's activities and setting that could influence play activities in the group; and finally, we marked (c) all instances in which the teachers describe how the difficulties encountered were examined further. Particular attention was paid to any kind of governance tool (see Paananen, 2017b) that played a role in executing the planned play activities. Additional ethnographic field notes from Anna's study during the 2003-2004 school year were used as complementary data to contextualise the findings.

Most play-based activities in the group had a stable place in the weekly schedule, which teachers were committed to following. The children also knew the schedule (see Rainio, 2010). In contrast, in Maiju's study, although there was a weekly schedule, plans were often cancelled, for example, when a staff member was absent. At Anna's site, the playworld activity took place every Wednesday and Thursday morning after breakfast (approx. 9.30-11 am). Similarly, City Play, another central play activity in the class, had a permanent place on the weekly calendar, although it was also a flexible form of play that they often initiated if there was extra time available during the day. Adults had an active role in both of these play activities, although it was different in each of them. The teachers describe City Play in their 2002-2003 Annual Report as follows:

City Play turned into a shared activity for us when the adults started to take an active role in developing it. Children got very intrigued by this turn, and then the play started to develop fast. On the other hand, one strength of this form of play is that there is no ready-made model for it, and the adults don't really participate in developing the plot. Everyone can 'live' this play in their own way, like families live their lives. [---] City Play is a secure choice if we have 'free' days between our projects. City Play does not even suffer if it has been forgotten for some time; the children are always equally pleased to construct the town. [---] City Play in this class is children's own form of play that we hope will have its place here in the future too. (From the Annual Report 2002-2003)

In this excerpt, one can detect the established place of City Play within the group's daily activities. The construct was established in such a way that it has become a governing tool; the children know how to engage in City Play even if adults do not participate as much as they did previously. The children have an adequate understanding of what City Play entails, although there is room to develop it further.

In Maiju's study, one finding was that when the children's individual ECEC plans became entangled with other kinds of local policies, they formed micro-policies that inhibited these children's participation in shared play activities (e.g., in Oliver's case described above, it had been agreed that Oliver would not exit the building to go outdoors at the same time as his peers). In the class that Anna studied, special supports for individual children were typically built into developmental tasks for the teachers to work on within the play activity. The teachers describe such a situation in relation to playworld planning:

Parallel to the objectives (for playworld) we set for the whole group, we used children's individual plans. We chose two child groups that were different from the other kids and needed adult guidance and support. We decided to follow the first group more carefully; it 
included four children who were reserved and needed encouragement. The other group consisted of four children who experienced significant challenges in collaboration and social interaction. Two of them were hyperactive with a tendency to act impulsively. [---] These follow-up groups were very different, and we deliberated on how we could create a play activity that supports the developmental plans of all these children. We ended up creating characters (played by adults) within the play, who would act in very similar ways as these children. Simultaneously, we followed the children's actions and reactions in different situations. Originally, we developed three adult characters: one shy; one inconsiderate type who is hyperactive; and a "Who cares, I want it all" type. These plans went awry because of the sick leave (of the personnel), so we combined two of these roles into one. The result was a character called Ines, who was shy and reserved, and Mirkku, who was hyperactive, impulsive, and curious. (From the Annual Report, 2002-2003)

In contrast to Oliver's case, at Anna's site, national policies of play and national policies related to the individual support of children were intentionally combined in the local playworld activity. The needs of children requiring special support were considered $t$ when planning the play, and supported during the play. Yet, the playworld still remained open in a way that it was not only the teachers who could decide what happened there. More specifically, these two national policies materialized in the daily life of the class as a governing tool of playworld - a certain shared understanding of organizing daily life. The governing tool aspect of playworld seemed to lead to a micro-policy of resilient play where surprising interferences, such as absent staff members, did not prevent playing it, and the children's varying abilities did not prevent anyone from being part of the play.

When challenges were encountered in Maiju's example, the play activities remained on the schedule; however, they often had to modify them. In Anna's example, teachers had to change their original plan for the characters because several personnel were absent. This required improvisation in situ to collectively re-plan the activity at short notice. To do so, there needed to be a place for continual planning in the teachers' schedule and a chance to re-negotiate situations. In such situations, the teachers actively chose to retain playworld. The playworld activity, was adequately flexible in its combination of improvisation and careful preplanning (see Lindqvist, 1995). The teachers conducted a weekly planning session where they reflected on the week's play activities and loosely prepared the next week. During these meetings, teachers followed-up the motivation of each group and individual children (Rainio, 2010). We claim that teachers need established long-term structures and other continual supportive elements that enable the sustainability of play in situations involving conflict and overlapping aims. In-service education and regular consulting support for the teacher team, for example, provided by the city in collaboration with the university, helped develop these practices as a regular part of the class.

Indeed, the local city administration and leaders of the school were very supportive of this group's play-based pedagogies. It thus received clear external support. In their annual report, teachers described how they felt that the support from both the school's principal (Maria) and the head of the municipality's ECEC services (Leila) were central to developing their work: 
The most tranquil phase in our team counseling started at the end of the second year when Leila returned to work. For the first time, we had a situation in which both our advisors, Leila and our school principal Maria, full-heartedly supported our team. The next one and half years we were very productive, not even the replacements in our personnel slowed down the progression in the contents of the pilot study. (From the Annual Report 2002-2003)

Today, 15 years after the study and with about two-thirds of the personnel replaced, the class still follows the play-based curriculum in the school and develops city play and playworlds in the class. We suggest that the supportive structures created on the local political level in collaboration with research- and theory-based in-service education have created a preschool culture in the class that sustains itself year after year despite challenges currently facing the sector. The crucial question now is what can be learned from this case? How can such sustaining and persisting play-based practices be embedded in ECEC classrooms more widely?

What kinds of practices and arrangements would support you to participate in or follow children's play?

\section{Culmination}

We have examined how different levels of policy aims become mediated and turned into micropolicies shaping pedagogical choices made by teachers in the daily activities of preschools. We have shown how possibilities for adults to participate and support children's play are entangled with other policy aims, leading to either inhibiting or enabling this participation. As we noted in the first case study, although the national policy highlights play, and the personnel consider play an important part of daily activities of the ECEC, it does not necessarily lead to practices in which play is actively supported. The second case illustrated that for play to have a more secure placement in daily activities, it needs to be intentionally and carefully combined with other local policies and aims posed. This is not an easy task if we want to avoid play having only an instrumental value.

Although there were other elements in Anna's study that possibly contributed to making play such a sustained activity in the classroom (see Rainio, 2008b, Lindqvist, 1995; Ferholt et al., 2019) we have focused on the micro-policies that helped make play sustainable. We conclude that at least four policy-level factors seemed crucial for play to receive such persistent recognition:

- Play activities turned into governing tools with an established place in the routines of the class. There were named, recognized, and shared play activities with their own rules and ways of acting that were actively chosen by the children and adults each week: city play and playworld.

- These play activities were based on explicit and supported long-term development work by practitioners, the city municipality, and the researchers.

- Teachers received external support and had a devoted space and time for team counseling during the pilot study.

- There was a secured place and time for teacher planning, reflection, and documentation weekly and long-term. In these sessions, many other ECEC policy aims and tasks could be integrated into the schedule and to these play activities. The challenges faced by the 
teachers in their work could also be dealt with in ways that did not easily destroy or cancel shared play.

Making meaningful pedagogical choices in preschools is not just a matter of good will or the preschool teachers' pedagogical competence. It is also not solely a matter of support from the national ECEC policy. Instead, there is a need for explicit, supportive local policies helping teachers create governing tools that help achieve desired pedagogical aims (e.g., adult participation in play) while meeting other competing ECEC aims (such as efficiency) that often contradict pedagogical aims. In this Chapter, we have given some perspectives on such micro-policies in relation to play. There remains a need to systematically study different play-based curricula in various settings, both in Finland and internationally, to learn from the persistency of these cases and develop appropriate teaching practices to support play.

\section{References}

Annual Report (2002-2003). Unpublished Annual Report written by the Preschool Personnel for the City Administration.

Ferholt, B. \& R. Lecusay. (2010). "Adult and Child Development in the Zone of Proximal Development: Socratic Dialogue in a Playworld." Mind Culture and Activity 17 (1): 59-83.

Ferholt, B., Nilsson M., \& Lecusay, R. (2019 In Press). Preschool teachers being alongside young children: The Development of adults' relational competences in playworlds. Forthcoming in S. Alcock and $\mathrm{N}$. Stobbs (Eds). Rethinking Play as Pedagogy. Routledge.

Hakkarainen, P. (2004). Narrative learning in the fifth dimension. Critical Social Studies - Outlines, 2004(1), 120.

Hakkarainen, P. (2009). Development of motivation in play and narratives. In Blenkinsop, S (Ed.), The imagination of education. Extending the boundaries of theory and practice (pp. 64-78). Newcastleupon Tyne: Cambridge Scholars Publishing.

Hay, C. (2004). Common Trajectories, Variable Paces, Divergent Outcomes? Models of European Capitalism under Conditions of Complex Economic Interdependence, Review of International Political Economy, 11(2), 231-62.

Hännikäinen, M. (2007). Creating togetherness and building a preschool community of learners: The role of play and games. In T. Jambor \& J. Van Gils (Eds.) Several perspectives in children's play. Scientific reflections for practitioners (pp. 147-160). Antwerpen and Apeldoorn: Garant.

Kalliala, M. (2005). Play culture in a changing world. Berkshire: McGraw-Hill Education.

Lindqvist, G. (1995). The Aesthetics of Play. A Didactic Study of Play and Culture in Preschools: Acta Universitatis Upsaliensis, Uppsala Studies in Education 62. Stockholm: Almqvist \& Wiksell International. 
National Core Curriculum for Early Childhood Education and Care 2016. Helsinki: Finnish National Board of Education.

Onnismaa, E-L \& Kalliala, M. (2010). Finnish ECEC policy: interpretations, implementations and implications, Early Years, 30:3, 267-277, DOI:10.1080/09575146.2010.511604

Paananen, M. (2017a). The imaginaries that survived: Societal roles of early childhood education in an era of intensification. Global Studies of Childhood (ahead of print) DOI: 2043610617704934.

Paananen, M. (2017b). Imaginaries of Early Childhood Education: Societal roles of early childhood education in an era of accountability. Helsinki Studies in Education (3). Helsinki: Faculty of Education.

Paananen, M., Lipponen, L., \& Kumpulainen, K. (2015). Hybridisation or ousterisation? The case of local accountability policy in Finnish early childhood education. European Educational Research Journal, 14(5), 395-417.

Paananen, M. \& Rainio, A. P. (2018) Adult-child joint play in turmoil: Can play overcome the challenges of performativity in Finnish ECEC? A paper presented at the American Educational Research Association (AERA) Conference, 16.4.2018, New York, USA.

Rainio, A. P. (2008a). From resistance to involvement: Examining agency and control in a playworld activity. Mind, Culture, and Activity, 15(2), 115-140.

Rainio, A. P. (2008b). Developing the classroom as a figured world. Journal of Educational Change 9(4), 357364.

Rainio, A. P. (2010). Lionhearts of the Playworld. An ethnographic case study of the development of agency in play pedagogy. Studies in Educational Sciences 233. Institute of Behavioural Sciences. University of Helsinki.

Rainio, A. P. \& Hilppö, J. (2017). The dialectics of agency in educational ethnography. Ethnography \& Education 12(1), 78-94.

Vygotsky, L. S. (1978). Mind in society: the development of higher psychological processes. Cambridge: Harvard University Press.

Vygotsky, L. S. (1987). Imagination and its development in childhood. In R.W Rieber \& A. S. Carton (Eds.), The collected works of L. S. Vygotsky, vol. 1, (pp. 339-350). New York: Plenum Press. 